\title{
LA MARCA DE LA INCERTIDUMBRE
}

Carmen Revilla

Universidad de Barcelona

Los acontecimientos que han inaugurado el siglo XXI no son tranquilizadores: el multitudinario y reiterado rechazo a la política de globalización del G8, el ataque y derrumbe de las torres gemelas de Manhathan, la guerra de Irak, la matanza del 11 de marzo en la estación de Atocha no son sino índices puntuales de un presente inquietante, al que asistimos como espectadores, que protagonizamos sin llegar a hacer de él experiencia, testigos de imágenes y destinatarios de medias verdades, carentes de los recursos que permitirían integrarlo y modificar nuestra relación con el mundo.

Son, todos ellos, conflictos que exhiben la culminación de tendencias cuya raíz se hunde en nuestra historia próxima, y no tan próxima. El pasado reciente permite pensarlos como núcleos en los que habrían cristalizado problemas ya avistados y, sin duda, abordados también, aunque en circunstancias que, al no identificarse siempre con las nuestras, tienden a ocultar su urgencia con el velo de una «teoría» que parece haber perdido lo que originariamente tuvo de "participación». Cuando se multiplican los estudios sobre problemas relativos a la violencia o la interculturalidad, sobre las fronteras entre información y comunicación, sobre las condiciones de posibilidad del diálogo o sobre los límites y la incapacidad misma de experiencia, se echa en falta algo: un modo de reflexión, tal vez difícilmente definible, capaz de encarar la sobresaturación de propuestas que paraliza con su exceso, de hablar en primera persona con el lenguaje cuya fuerza nacería de la verdad a la que las cosas responden, haciéndose así eficaz. Como un nuevo síntoma, el índice de participación en las recientes elecciones europeas parece confirmar que algo sucede en el seno de nuestras sociedades occidentales. 
Sin pretender el tratamiento exhaustivo de estos problemas que marcan la actualidad ${ }^{1}$, quisiera simplemente, a modo de esbozo de posibles perspectivas, recordar la existencia de algunos textos en los que la lucidez en la percepción del presente permite identificar recursos latentes y fuentes de energía que hacen de la mirada que recogen una inestimable compañía. Sus autores, poniendo en juego su experiencia, hacen de la descripción de lo real que ofrecen un compromiso personal con la actualidad, y en este marco dibujan opciones muy diferentes cuyo denominador común sería el constituir una respuesta a lo que María Zambrano consideraba la tarea de Europa: aprender a vivir en el fracaso de una irrenunciable vocación utópica que nacería del doble impulso que constituye su raíz: la herencia griega y la cristiana: «La más grave enfermedad europea será la caricatura de su íntima esperanza, la que envuelve la traición a su utopismo revolucionario de resurrección. Enfermedad que bajo la aparente energía oculta la desgana, la fatiga de seguir viviendo en tensión [...] embriaguez que haga olvidar la distancia insalvable entre las dos ciudades, la de Dios siempre en el horizonte, y la de la tierra, siempre en edificación [...] Barbarie monista, falsificada mística que suplanta a la permanente esperanza de resurrección y a la consustancial utopía creadora. Cansancio de la lucidez y del amor a lo imposible y abandono del saber más peculiar del hombre europeo: el saber vivir en el fracaso»².

Con estas palabras cerraba la autora el escrito de 1942 La esperanza europea, una reflexión sobre la identidad de Europa y la raíz de sus conflictos. La recuperación del saber al que apela pasaría por la recuperación de esta doble herencia: la irrenunciable vocación griega a la transparencia, a la razón, y la esperanza cristiana que es "vocación para la vida», decisión de ver y aceptar el "orden de las cosas» sin renunciar a un "constitutivo idealismo» que hace de su historia "puro horizonte». "Preso en su doble amor: al mundo invisible, al horizonte, y al de acá abajo, con el que tenía fija su voluntad», el hombre europeo ha de vivir entre "las cenizas de sus sueños», "huellas en la arena del tiempo de su anhelo» ${ }^{3}$ en cuyo desciframiento se juega la posibilidad de la existencia.

\section{Certezas y creencias}

Uno de los autores que, en una perspectiva ciertamente diversa y con objetivos también muy diferentes, asume, sin embargo, de manera explícita la necesidad de reconocer la procedencia a la hora de enfocar y hacer frente a

\footnotetext{
' Por citar sólo alguna de las más recientes publicaciones que ilustran la preocupación por el presente desde puntos de vista muy diferentes: La filosofía en una época de terror. Diálogos con J. Habermas y J. Derrida, editado en Taurus; GLUCKSMANN A., Occidente contra Occidente, también en Taurus; FERNÁNDEZ-BUEY F., Guía para una globalización alternativa, Ediciones B, 2004; LAMO DE ESPINOSA E., Bajo puertas de fuego. El nuevo desorden internacional, Taurus, 2004.

${ }^{2}$ ZAMBRANO M., La agonía de Europa, Madrid, Trotta, 2000, pp. 84-85.

${ }^{3}$ O.c., pp. 81-82.
} 
los requerimientos del presente es, sin duda, Gianni Vattimo. La acogida que sus escritos reciben pondría de relieve su capacidad para sintonizar con la actualidad; de aquí, pues, el interés de atender a sus más recientes aportaciones en las que da expresión al alcance y los límites de una importante línea de pensamiento, como lo es la hermenéutica a la que se adscribe.

En la Introducción a Después de la cristiandad, colección de ensayos elaborados a partir de 1996 y publicados con este título en inglés en 20024, Vattimo se sitúa en el horizonte abierto por Creer que se cree $^{5}$, así como en el último de sus trabajos, Nihilismo y emancipación, que recoge una serie de ensayos recientes $^{6}$, en los que reflexiona sobre el alcance ético-político de una posible conexión entre la experiencia del final de la modernidad, que recoge el pensamiento posmetafísico introducido por Nietzsche y Heidegger, y el perceptible renacer de formas de religiosidad diversas en nuestras sociedades. Y se diría que se sitúa en este marco desde el comienzo, no solamente por la incorporación del tema de la religión como elemento decisivo en su argumentación, sino, sobre todo, porque este elemento lo introduce bajo el signo de la creencia y la incertidumbre, patente en la paradójica ambigüedad del título y, desde luego, no ajena al carácter biográfico de este libro.

Vincular el proyecto de emancipación característico del pensamiento occidental con el nihilismo que describe su culminación resulta, ciertamente, provocador. La provocación es el enunciado, por parte de quien dice de sí mismo que "es muy bueno poniendo títulos», de una situación en la que la extinción del «fantasma de la objetividad» como criterio de verdad coincide con la apertura del campo de la experiencia religiosa y el retorno de lo sagrado, situación -dicho sea entre paréntesis- que Zambrano ya había destacado en los años cuarenta, precisamente en el último de los ensayos que componen La agonía de Europa en el que reflexiona sobre el arte que, en su forma actual, mostraría, a juicio de la autora, que se ha llegado a los confines de lo humano y se ha producido, justamente por ello, un «retorno a lo sagrado». El desafío al que Vattimo se enfrenta es el de pensar esta conexión atendiendo a las posibilidades liberadoras que el final de la metafísica, la «muerte de Dios» preconizada por Nietzsche, y el establecimiento del mundo babélico de la modernidad tardía implican. El nudo de la propuesta del autor afecta a una concepción del cristianismo, y más específicamente del catolicismo, solidario con el destino de la modernidad occidental en la medida en que constituye la herencia sobre la que la sociedad laica y secularizada se sostiene; así entendido, el cristianismo aparece como raíz esencial de la secularización occidental y «condición de posibilidad de ser laicos», garantizando un espacio de legitimidad a las diferencias y promoviendo ámbitos de libertad; asumir esta solidaridad, que hace

\footnotetext{
${ }^{4}$ VAtTIMO G., Después de la cristiandad. Por un cristianismo no religioso, Barcelona, Paidós, 2002.

${ }^{5}$ VATTIMO G., Creer que se cree, Barcelona, Paidós, 1996.

${ }^{6}$ VATTIMO G., Nihilismo y emancipación. Ética, política y derecho, Barcelona, Paidós, 2003.
} 
del «pensamiento débil» una versión filosófica del cristianismo en la actualidad, supone acentuar en éste sus caracteres de espiritualización y debilitamiento.

En esta propuesta, los «procesos de debilitamiento», aludidos genéricamente con el término «nihilismo» como ubicación en una ontología del acontecer en la que se diluyen las estructuras «fuertes» de orden ontológico y ético, no tendrían necesariamente que ver, a mi juicio, con una necesaria reducción de la ontología a la ética del diálogo y la consiguiente supresión del elemento trascendente. Frente al resurgir de nuevos «fundamentalismos» en algunas formas de religiosidad «popular», frente al retorno del mito y la afirmación de la absoluta alteridad, como fenómenos que vienen acompañando y modulando el desarrollo del nihilismo, se trataría más bien de subrayar que el Dios cristiano se revela en la encarnación y ésta es kénosis, abajamiento e inmersión en la historia que liga esencialmente los procesos de salvación e interpretación.

Lo que en esta opción hay de ruptura con los contenidos dogmáticos o con la formulación de deberes positivos en una determinada confesión religiosa parece derivar, antes que de la apuesta por la interpretación y el diálogo -que, en todo caso, supone en los interlocutores que intervienen el saberse implicados y conscientes de su identidad, aunque sin atribuirse privilegios-, del modo en el que la fe viene asumida como experiencia personal, en un "sentido profundamente marcado por la incertidumbre de la opinión». La expresión «creer que se cree» expresa la dificultad de conjugar creencia y convicción, opinión y certeza. Vattimo considera «sospechoso» atribuir contenido fuerte a una fe en la que simplemente se cree en sentido débil; la ambigüedad en la que se mantiene se diría que reside en la posibilidad de introducir como alternativa el fortalecimiento de esta creencia mediante la debilitación de sus contenidos. La visión de la historia como disolución del lema «amicus Plato sed magis amica veritas» y de su culminación en el nihilismo como perspectiva en la que la verdad objetiva se consuma en la expresión de diferentes amistades ilustraría esta alternativa, aunque el reconocimiento de la amistad como factor decisivo de la verdad exija el recurso a la caridad, puesto que ésta se redefine en términos de hospitalidad en un mundo que acoge una pluralidad de presencias debilitadas también.

El alcance de estas propuestas se habría de valorar atendiendo a los distintos estratos en los que se articula la argumentación del autor, que van del plano socio-político al de la discusión teológica, trabados mediante una perspicaz lectura de la tradición filosófica y una sólida familiaridad con el pensamiento contemporáneo. Aquí quisiera destacar lo que tienen no sólo de síntoma, sino de voluntad de pensar aceptando el desafío de un contexto en el que la irrupción de lo sagrado convive con una forma de racionalidad consciente de su necesidad y carencia de recursos.

Es en este contexto, cuando la incertidumbre vital alcanza a la certeza de las convicciones, sin embargo, en el que podría pensarse en la posibilidad de encontrar otros testimonios, conscientes también de esta dificultad a la que 
habrían ofrecido una respuesta comprometida con la razón, que reivindica la fuerza de su debilidad. A ellas se refiere Chantal Maillard cuando habla de «una razón vulnerable -de principios no rígidos- cuya fuerza estriba precisamente en su vulnerabilidad», señalando cómo "lo débil es fuerte en su porosidad, en su maleabilidad, en su flexibilidad ${ }^{7}$. Aunque con estas observaciones introduce una presentación del pensamiento zambraniano, podrían servir para orientar la lectura de otra autora, Simone Weil, cuya vinculación al «pensamiento débil $»^{8}$ abre, sin embargo, una perspectiva singularmente diferenciada en este ámbito.

Durante su estancia en Marsella, tras la entrada de los alemanes en París, Simone Weil escribía en las anotaciones que constituirán sus Intuiciones precristianas, recientemente traducidas: «Hoy [...] hemos perdido la idea de que la certeza absoluta es exclusivamente propia de las cosas divinas. Hoy queremos esa certeza para las cosas materiales. Para las cosas relativas a Dios nos basta con la creencia. Bien es verdad que la simple creencia acaba teniendo la fuerza de una certeza cuando se la lleva al punto de fundición blanca con el fuego de los sentimientos colectivos, pero no por ello deja de ser una creencia. Su fuerza es engañosa» ${ }^{9}$.

Con estas afirmaciones Weil, interesada en encontrar en el pensamiento griego el núcleo de lo que a su juicio sería la inspiración cristiana, intenta destacar el hecho, como indica a continuación, de que «nuestra inteligencia se ha vuelto tan torpe que ni siquiera somos capaces ya de pensar que puede haber una certeza auténtica, rigurosa, acerca de algunos misterios incomprensibles», sustituyéndola por convicciones radicadas en las ficciones que la vida social, a través de la propaganda y la creación de sentimientos colectivos, genera e impone. Su propuesta, que implica una inversión radical de los planteamientos que han dominado la modernidad, se apoya en el reconocimiento de un doble nivel de realidad al que corresponde un doble registro epistemológico: el plano de las certezas y el de las creencias. En su obra será una constante la preocupación por discernir ambos niveles y por alertar respecto a los peligros que encierra su confusión: la renuncia a los objetos que pueden satisfacer la necesidad de certeza, aspecto que le interesa particularmente cuando redacta estas notas, acompañada de la consiguiente incapacidad de vivir en la incertidumbre e inseguridad de la existencia, situación que, a su juicio, origina en la vida social, víctima de la seducción de la mentira, tendencias idolátricas, o bien parálisis e inanición.

Entre sus escritos de carácter histórico-político, en los que aborda este último aspecto, se podría destacar, en este sentido, el fragmento, recogido con el

\footnotetext{
${ }^{7}$ MAILLARD Ch., «Las mujeres en la filosofía española» en ZAVALA I. M. (coord.), Breve historia feminista de la literatura española (en lengua castellana), V, Barcelona, Anthropos, 1998, p. 271.

${ }^{8}$ Véase el ensayo de DAL LAGO A., "La ética de la debilidad. Simone Weil y el nihilismo» en VATTIMO G. - ROVATTI P. A., El pensamiento débil, Madrid, Cátedra, 1988.

${ }^{9}$ WEIL S., Intuiciones precristianas, trad. de Carlos Ortega, Madrid, Trotta, 2004, pp. 109-110.
} 
título Reflexiones sobre la barbarie, que redacta posiblemente en 1939, el año en el que, tras la invasión de Checoslovaquia por parte de Hitler, abandona el pacifismo radical que había defendido, consciente de la amenaza que se cierne sobre la civilización europea. En este breve ensayo la autora propone una revisión de la noción de «barbarie» que permita objetivar el alcance del peligro que el nazismo representa y esbozar la estrategia que pueda responder adecuadamente al mismo. El punto de partida de su argumentación se lo proporciona la constatación de convicciones, generalizadas y vigentes, cuyo error habría generado la incapacidad que observa en sus contemporáneos para hacer frente a este peligro: por una parte, la creencia de que se vive un momento único en la historia de la humanidad, en virtud de «una mayor potencia técnica, o una especie de decadencia moral, o cualquier otra causa ${ }^{10}$, por otra, "la creencia contraria», igualmente peligrosa y falsa, "en una disminución progresiva de la barbarie en la humanidad que se dice civilizada», y, vinculada a esta confianza en el "progreso», «la fe ciega en una raza, en una nación, en una clase social, en un partido» ${ }^{11}$. La primera de estas convicciones paraliza por falta de resortes, la segunda por la ilusoria confianza en una resolución de los conflictos que eximiría de la acción responsable y personal.

Ante estas actitudes Simone Weil recurre a la historia, cuyo testimonio invalida su posible veracidad: ningún presente es excepcional y nada permite pensar que, en ausencia de una acción consciente y eficaz, las recurrentes pesadillas del pasado dejen de reiterarse. El texto, como en otros muchos momentos, es una llamada a afrontar la desnudez de los hechos, cuya verdad ocultan las creencias falsamente convertidas en certezas vitales. Europa atraviesa circunstancias trágicas, el riesgo de una guerra «ilimitada», según su expresión, no constituye, sin embargo, un fenómeno sustancialmente nuevo: el objetivo alemán de dominación universal tuvo su precedente y modelo en Roma. Sin embargo, la historia que, como narración de los vencedores, proporciona estos modelos encierra también «espejos» en los que la dinámica de lo real se muestra e incluso, aunque en aisladas y esporádicas ocasiones, "gotas» de un pasado aún vivo que, como savia, podría revitalizar el presente. A la recuperación de estos gérmenes de vida dedicará sus últimos años, empeñada en una tarea de traducción y búsqueda de las palabras que permitan nombrar lo real, convencida de que los problemas políticos se retrotraen a una cuestión de lenguaje.

En este sentido habría que recordar el hecho de que Zambrano ya alertaba también respecto a lo más «lamentable» de nuestra cultura: «su falta de transformación del conocimiento puro en conocimiento activo que alimente la vida del hombre que lo necesita ${ }^{12}$. Para hacer frente a esto introdujo un lenguaje

\footnotetext{
${ }^{10}$ WEIL S., «Réflexions sur la barbarie», en Écrits historiques et politiques, París, Gallimard, 1960, p.63.

${ }^{11}$ O.c., p.64.

${ }^{12}$ ZAMBRANO M., "La Guía, forma del pensamiento», en Hacia un saber sobre el alma, Madrid, Alianza, 2000, p. 74.
} 
inédito en la filosofía, consciente de que «una de las más tristes indigencias del tiempo actual es la de metáforas vivas y actuantes; esas que se imprimen en el ánimo de las gentes y moldean su vida» ${ }^{13}$, en un gesto de libertad y compromiso que no es ajeno a un rasgo de su pensamiento que nos la acerca particularmente, situando su aportación, tan personal e incluso «intempestiva», en el centro de una corriente teórica que recorre, con modulaciones muy diversas, la filosofía de las últimas décadas: la decisión de leer el presente a la luz del pasado, la convicción de que «el privilegio de tener antepasados» permite contar con la presencia viva y eficaz de interlocutores activos que responden a nuestras necesidades y requerimientos, que nos interpelan y acompañan posibilitando el pensar. «El hombre posee el privilegio de tener antepasados; somos siempre hijos de alguien, herederos y descendientes [...] Y es que tener cultura, estar en una cultura, es tener detrás de la vida individual de cada uno un tesoro a veces anónimo, a veces con nombre y figura. Es poder recordar, rememorar. Poder también, en un trance difícil, aclarar en su espejo nuestra angustia e incertidumbre ${ }^{14}$, nos dice.

La celebración, justamente durante el año 2004, del centenario del nacimiento de esta autora ofrece la ocasión de reparar en el modo en el que responde del tesoro de esta herencia, acudiendo a figuras que, como Séneca, renacen «a causa de la profundidad de su arraigo ${ }^{15}$, que «sentimos por encima de nosotros, pero cercano, familiar» ${ }^{16}$ y vuelven porque se les busca, encerrando una versión de lo humano que necesita de interpretación y desciframiento. Séneca, para Zambrano, "es propiamente un mediador, un mediador, por lo pronto, entre la vida y el pensamiento, entre ese alto logos establecido por la filosofía griega como principio de todas las cosas y la vida humilde y menesterosa ${ }^{17}$ al que se dirige como «depósito de nuestra esperanza y de nuestro anhelo ${ }^{18}$, imprescindible cuando impera la perplejidad que «aparece en época avanzada de una cultura» y "es una debilidad del ánimo que no proviene del conocimiento sino de la relación entre el conocimiento y el resto de la vida que queda impermeable a él» ${ }^{19}$. También al presente parece que «le falta ese último móvil que mueve a la vida, que le arrastra y saca de sí»»" la actualidad del diagnóstico zambraniano invita a tomar en consideración la posibilidad de encontrar en su obra una presencia mediadora también, acentuando el sentido en el que converge con otros desarrollos del pensamiento contemporáneo.

\footnotetext{
${ }^{13}$ ZAMBRANO M., «La metáfora del corazón», en Hacia un saber sobre el alma, ed. cit., p. 59.

${ }^{14}$ ZAMBRANO M., Séneca, Madrid, Siruela, 1994, 21.

${ }^{15}$ O.c., p. 24.

${ }^{16}$ O.c., p. 29.

${ }_{17}$ O.c., p. 31.

${ }^{18}$ O.c., p. 26.

${ }^{19}$ ZAMBRANO M., "La Guía, forma del pensamiento», en Hacia un saber sobre el alma, ed. cit., pp. 94-95.

20 Ibid.
} 


\section{2. «El privilegio de tener antepasados»}

«Contra el futuro que se presenta ante nosotros vociferante y seguro de sí, habrá que contar siempre con otro porvenir aún en ciernes y cuyo crecimiento debemos proteger. Las crisis de violencia nunca son más que los malos cuartos de hora de la historia; no contribuyeron a los más mínimos progresos humanos más de lo que los vendavales contribuyen al crecimiento de la mies. Después de cada tormenta, la humanidad reanuda humildemente su tarea interumpida, que consiste precisamente en preservar las fuerzas aún vivas del pasado y en dirigir su lenta evolución hacia el mañana» ${ }^{21}$.

Estas palabras de Marie Yourcenar podrían servir para introducir esta reflexión sobre el modo en el que María Zambrano se acerca a la tradición específicamente filosófica. En primer lugar porque, creo, suscribiría la distinción entre el futuro -que se nos impone, como máscara de un Dios desconocido- y el porvenir, que se gesta en el tiempo; pero, sobre todo, porque parecen cifrar la tarea de la humanidad en dar cauce, justamente, al tiempo, en hacer del futuro porvenir contribuyendo a su crecimiento, en el cuidado de la fuerza viva del pasado y de su capacidad de abrirse paso. A esta tarea, propiamente humana, corresponde la lectura, forma específica de experiencia del pasado y relación con él que, cuando respeta la vitalidad del mismo, prosigue su movimiento de modo que la tradición que así constituye es apertura esencial de horizontes. En esta tarea, la existencia de antepasados es, para Zambrano, un privilegio, nos dice, pero un privilegio permanentemente acechado por el riesgo de su sobresaturación, por el peligro de no respetar su «fuerza aún viva», de detenerla y estancarla.

La lectura zambraniana del pasado se mueve, a mi modo de ver, bajo la tensión de una doble necesidad: la de su presencia constitutiva y la de acordarse a su despliegue. En virtud del primer aspecto, esta lectura ocupa en el pensamiento de la autora un lugar relevante, en función del segundo, adquiere unas características peculiares, que, aunque distanciadas del rigor historiográfico, orientan la atención al tema de la historia. Sobre estos dos puntos propondría, pues, reflexionar. Anticipo que la clave de mi propuesta es que, para Zambrano, la presencia del pasado, nuestra pertenencia a la tradición, es un hecho con el que hemos de habérnoslas, pero no un privilegio; el privilegio es «tener antepasados», es decir, la posibilidad de encontrar en la tradición presencias vivas y eficaces, interlocutores activos que responden a nuestras necesidades y requerimientos, que nos interpelan también. Esta forma consciente de situarse en la tradición y contar con ella acerca a la autora a algunas corrientes del pensamiento actual e invita a considerar la particularidad de sus posiciones y el sentido de su aproximación a la historia del pensamiento.

Si se atiende a las corrientes de pensamiento que han dominado las últimas décadas del siglo XX, no es necesario insistir en el hecho de que no es factible

${ }^{21}$ YOURCENAR M., «Fuerzas del pasado y fuerzas del porvenir» (1940), en Peregrina y extranjera, Alfaguara, 1999. 
prescindir del pasado, pasando a primer plano el problema de la relación con el mismo a través de la tradición textual, y más concretamente de la filosofía; a ésta se le supone una vida, una capacidad de pervivir y adquirir actualidad sobre la que vale la pena detenerse, a partir de la pregunta en torno a dónde y en qué radica la vida de los textos.

Como se sabe, la relación de Zambrano con la historia está, desde el comienzo, mediada por la presencia de Ortega. En el artículo Don José, redactado con ocasión del fallecimiento de quien siempre consideró su maestro, afirma: "Siempre tuve terror de la historia, hasta que le oí. Y me parecía oyéndole que el aceptar la historia fuese entrar en razón $»^{22}$. A pesar de las distancias en el planteamiento mismo de los dos autores, Zambrano conoció y compartió el que «el hombre es, por encima de todo, heredero ${ }^{23}$, de modo que la filosofía en la que realiza su también esencial aspiración al saber ha de hacerse cargo de esta herencia, a través del desarrollo de una forma de racionalidad narrativa que permita su transmisión, que posibilite que el pasado pase, adquiera fluidez y se incorpore a la proyección de un futuro configurado en decisiones libres ${ }^{24}$.

En todo caso, sin embargo, cuando María Zambrano se refiere al filosofar como tarea subraya lo que en la acción del pensamiento hay de «destrucción»: «Si hubiera de elegirse una entre todas las acciones propias del filosofar, del pensamiento en su máxima pureza y universalidad, sería sin duda la destrucción», una destrucción que, añadirá, es «creadora» porque, al destruir lo que «cierra el paso» al vivir humano, abre el espacio «del respirar y el ver, y conjuntamente la donación de la palabra. La palabra indispensable que opera sobre la realidad que circunda al hombre, la más que humana, humanizadora palabra-pensamiento, pues ${ }^{25}$. Al ejercicio de esta forma del pensamiento obliga el carácter de determinadas épocas: «El hombre en épocas de acumulación tiende a ocultar el horizonte. Sería ello suficiente para delatar el atentado a la humana condición de la vía acumulativa de bienes, de propiedades, de posesión científica, incluida la adquisición de conocimientos y saberes. La avidez que se yergue desde la conciencia inerte, que se agazapa en su escondrijo» ${ }^{26}$.

La Ilamada de atención sobre los riesgos del exceso no es nueva. Ya Nietzsche -al que, como se recordará, la autora se había referido como «protagonista» de esos instantes de la historia en los que conviven la máxima «liber-

\footnotetext{
22 ZAMBRANO M., «Don José», en Insula, no 119, Madrid, 1955; recogido en Anthropos. Suplementos, $\mathrm{n}^{\circ} 2,1987$, p. 17.

${ }^{23}$ ORTEGA y GASSET J., "Ideas y creencias», en Obras completas, vol. V, Madrid, Revista de Occidente, p. 400.

${ }^{24}$ Sobre este punto pueden verse las sintonías entre la posición de Ortega en Historia como sistema y la de Zambrano en el prólogo a la segunda edición de El hombre y lo divino.

${ }^{25}$ ZAMBRANO M., «El horizonte y la destrucción», en Diálogos 11/4, 1975.

${ }^{26}$ Ibid.
} 
tad y riqueza ${ }^{27}$ - había alertado respecto a la «sobresaturación de la historia» y su diagnóstico de los efectos de la «enfermedad histórica» no puede pasarse por alto: el «espectáculo inabarcable» del pasado genera el debilitamiento, característico de la inmadurez o de la vejez prematura, propio de esa «mentalidad epigonal» que anula la «fuerza plástica» del presente, su capacidad creadora. Como se sabe, la propuesta nietzscheana, en el contexto del auge del historicismo cientifista, se centra en la recuperación de «la suprema fuerza del presente», porque sólo a partir de ella «está permitido interpretar lo pasado» ${ }^{28}$. Hay, sin embargo, en esta propuesta un supuesto que encierra algo de equivocidad: la fuerza del presente ¿en qué consiste?: por una parte, al parecer, en la capacidad de olvido que corresponde a la acción y a la vida, pero, por otra, se diría que, de manera muy sustancial, en el reconocimiento de la propia necesidad: el pasado es una necesidad de la vida, no del saber, y cuando éste adquiere una configuración gratuita, no sólo resulta innecesario, deforma también la relación entre la historia y la vida, entre el pasado que nos constituye y la apertura de futuro, obligando al pensar a asumir como tarea la destrucción del saber innecesario que lo obstaculiza, tarea a la que Zambrano se refería como específicamente filosófica.

Probablemente en lo que tienen de «intempestivas» las «consideraciones» de Nietzsche radique también su capacidad de integrarse en nuestra actualidad, cuando el problema del exceso de información ha adquirido unas formas específicas, claramente diferenciadas de las que presentaba a finales del XIX, aunque sin desaparecer por ello, incluso extremándose en algunos aspectos.

Se podría leer la hermenéutica, y no sólo en su versión gadameriana, así como la deconstrucción, como formas de hacerse cargo en el contexto actual de los problemas que de aquí se derivan. A ello respondería tanto el tránsito de la conciencia histórica a la conciencia de la historia efectual -tendente a permitir que los efectos del pasado realmente sean, tengan una efectividad eficaz-, como el reconocimiento de la textualización como lugar de experiencia y participación en una estructura heterogénea que, en la medida en que resiste a la apropiación, permite una práctica, también indefinida en sus efectos, de «producción de la verdad». A pesar de las distancias entre ambas orientaciones, las dos sitúan el pensar filosófico en esa «complicada relación» que, recientemente, Derrida ha caracterizado como «de pertenencia y de herencia, de ruptura y de dislocación ${ }^{29}$.

\footnotetext{
${ }_{27}$ ZAMBRANO M., "La destrucción de la filosofía en Nietzsche», en Hacia un saber sobre el alma, Madrid, Alianza, 2000, pp. 157 ss.

${ }^{28}$ Véase de nuevo en Sobre utilidad y perjuicio de la historia para la vida la propuesta de una historia crítica que defienda al presente de los peligros que entraña tanto la «historia monumental», en su búsqueda de grandes momentos y figuras, como la de tipo "anticuario», que se detiene en la intrahistoria; la primera daña el pasado, despreciando lo que no responde a su interés, y engaña, incitando a la temeridad y el fanatismo; la segunda, al limitarse a conservar, en lugar de producir vida, la momifica hasta hacerla perecer.

${ }^{29}$ DERRIDA J., «La democracia como promesa» (entrevista de 1994), en No escribo sin luz artificial, Valladolid, Cuatro, 1999, p. 102.
} 
No se trata de intentar conexiones, que, por otra parte, han sido ya objeto de atención ${ }^{30}$, sino de sugerir cómo la filosofía del siglo XX, que sitúa la comprensión en la «fusión de horizontes», comparte la experiencia de que «no pertenecemos a un tiempo», en la medida en que responden a una análoga experiencia del presente: «La afirmación según la cual soy a la vez arcaico, moderno y posmoderno es una manera de decir que no pertenecemos únicamente a un tiempo, que tenemos muchas edades y podemos vivir en una anacronía que no es necesariamente negativa. Hay que ser en cierta forma anacrónico para pensar lo contemporáneo $»^{31}$. En los dos casos la inevitable mediación de la objetividad de un texto -cuyo sentido se puede considerar inagotable o inaferrable- trae a primer término la conveniencia de reflexionar no sólo sobre esta noción -la noción de texto, y también la de sentido-, sino sobre el significado de la escritura y las determinaciones de su práctica, sobre el paradigma de la traducción para entender la lectura como acción en la que el sentido de un texto se cumple, sobre el peso, en fin, de lo-otro ${ }^{32}$, por utilizar la expresión derridiana, en la configuración del presente.

A la hora de llevar a cabo la re-lectura de estas dos posiciones, sin duda características y determinantes del pensamiento de la segunda mitad del siglo $X X$, se perfilan problemas respecto a los cuales la experiencia de lectura de Zambrano podría proporcionar orientaciones de singular interés, asumiendo el tiempo como presencia constitutiva del mundo humano y haciéndose cargo de las implicaciones que encierra.

Ya en el primero de sus libros, Horizonte del liberalismo, en la perspectiva de una reflexión política, instaba a contar con «la corriente del tiempo» como "germen de fecundidad», frente a las construcciones sistemáticas y aprioristas que, en su aspiración a la eternidad, renunciaban a arraigar en la realidad. Porque «el fermento del tiempo hace germinar la vida», la autora reclamaba «una política que reconozca este humilde y poderoso factor del tiempo» ${ }^{33}$. Se

\footnotetext{
${ }^{30}$ En nuestro contexto más próximo puede verse el trabajo colectivo, editado por GÓMEZ RAMOS A., Diálogo y deconstrucción. Los límites del encuentro entre Gadamer y Derrida, Cuaderno Gris, Universidad Autónoma de Madrid, 1998, así como de GÓMEZ RAMOS A., "Hermenéutica e incomprensión» en VEGA L. - RADA E. - MAS S., Del pensar y su memoria (Ensayos en homenaje al profesor Emilio Lledó), Madrid, UNED, 2001.

${ }^{31}$ DERRIDA J., «Otra libertad» (entrevista de 1997), en o. c., p. 106.

${ }^{32}$ En este sentido Derrida habla de la deconstrucción en términos de «justicia» ante la pregunta sobre «¿qué es ese algo que fuerza la deconstrucción de las cosas?», a la que responde diciendo: «Es lo otro; si podemos decirlo en una palabra es lo otro. Lo que Ilamo justicia es el peso de lo otro, que dicta mi ley y me hace responsable, me hace responder al otro, obligándome a hablarle. Así que es el diálogo con el otro, el respeto a la singularidad y la alteridad del otro lo que me empuja, siempre de una forma continua e inadecuada, a intentar ser justo con el otro (o conmigo mismo como otro)», en «La democracia como promesa», ed. cit., p. 97.

${ }^{33}$ ZAMBRANO M., Horizonte del liberalismo, Madrid, Morata, 1996, p. 212. En este sentido afirma: «Todo sistema de pensamiento -salvo singular excepción- era atemporal; levantaba su castillo ideológico sobre los descarnados, óseos cimientos de lo ideal, de lo supratemporal, desdeñando el humilde limo terrestre, donde el fermento del tiempo hace germinar la vida».
} 
trata de una urgencia característica de su presente, ante el «singular desprecio por el tiempo» que «ha sido patrimonio de las épocas pasadas» ${ }^{34}$; sin embargo, en su actualidad, encontraba también que la "posibilidad de la Historia», la voluntad de "descubrirla poco a poco», no responde al "gusto de hacer historia», sino a la "urgente necesidad de encontrarnos a nosotros mismos»; atendiendo a esta necesidad considerará que «en el estado cultural que hemos alcanzado, ya no es posible ser ingenuo. Antes de construir y para construir hay que mirar lo que nos hemos encontrado, y luego rechazar algunas herencias, y aceptar y superar otras», algo para lo que "urgen obreros del tiempo en sus dos direcciones: hacia el pasado, para que nos lo descubran sin deshacerlo, y hacia el porvenir, para sacarlo a la luz entre los desmontes del presente» ${ }^{35}$. Los, utilizando su expresión, "creadores del hombre» y «arquitectos que estructuren la atomización pasada» se encuentran, pues, ante una tarea de doble dirección para la que, como indica más tarde, parece haberse cerrado el horizonte, por lo que sugiere «partir, no de lo que se quiere, sino del conflicto actual $»^{36}$, ahondando en sus contradicciones, «penetrando en el subsuelo, donde las raíces se entrecruzan y confunden ${ }^{37}$, haciendo uso de una libertad que «no rompa los cables que al hombre le unen con el mundo, con la naturaleza, con lo sobrenatural», con los medios, en fin, de los que el ser humano «se nutre, se alimenta para crear su obra» ${ }^{38}$.

A pesar del carácter particular del ensayo -un análisis de las posibilidades del liberalismo político en circunstancias histórico-culturales muy precisas- y de lo incipiente de sus reflexiones, aquí pueden encontrarse indicaciones que serán decisivas en su propuesta de desarrollo de una forma de racionalidad que proporcione un pensamiento esencial a la vida. La decisión de situarse en el horizonte del tiempo frente al de la conciencia y de atender al fondo de realidad que la habita, descendiendo allí donde la vida es «oscura e irracional en sus raíces» sin ceder al «optimismo vital» que es también «pesimismo cognoscitivo ${ }^{39}$, la preocupación por salvar "la placenta del hombre con el mundo» que es «al mismo tiempo que sujeción, cable de la energía y de la gracia» ${ }^{40}$, marcan y orientan el desarrollo de sus reflexiones. Entre otras cosas, y aunque entonces creía haberse acercado a «esa zona segura, esa tierra firme, (que) es la que al individuo le permite ir y venir, y, cierto en su base, poder elegir; tener libertad, en suma», encuentra también la contradicción inherente a la libertad humana, la "paradoja» que supone el que "en su origen, ya la libertad, para tener realidad, se limita, se niega a sí misma» ${ }^{41}$.

\footnotetext{
${ }^{34} \mathrm{Ibid}$.

${ }^{35}$ O.c., p. 207.

${ }^{36}$ O.c., pp. 262-263.

${ }^{37}$ O.c., p. 264.

${ }^{38}$ O.c., pp. 266-269.

${ }^{39}$ O.c., p. 225.

${ }^{40}$ O.c., p. 232.

${ }^{41}$ Ibid.
} 
La relación zambraniana con el tiempo, con la tradición que da cauce y forma a su devenir en una cultura, estará, desde entonces, marcada por el empeño en salvar la libertad, la posibilidad de la vida en su trascender, en su capacidad de ir más allá, alimentándose, sin embargo, del fermento del tiempo. En los ensayos recogidos en Hacia un saber sobre el alma se pueden encontrar, en múltiples perspectivas, indicaciones en torno a la forma en la que esta preocupación inicial va a desarrollarse; entre ellos quisiera destacar La Guía, forma del pensamiento por varios motivos; en primer lugar porque en estas páginas centra el problema de la relación entre la libertad que la vida requiere como acción, "actividad incesante» dice, y los moldes, las formas, cánones o medidas, en los que se conserva y adquiere una transparencia que también le es necesaria y constituyen la cultura o la tradición en la que la vida de hecho se despliega. Para quienes no pueden limitarse a reproducir «anónimamente una cultura en su forma tradicional» pero tampoco son individualidades excepcionales, capaces de dar forma única e irrepetible por sí mismos a su existencia, para los «perplejos», esta relación es problemática: de hecho, "la perplejidad es una debilidad del ánimo que no proviene del conocimiento sino de la relación entre el conocimiento y el resto de la vida que queda impermeable a él. Perplejo indica más bien sobrado de conocimiento. En toda perplejidad hay deslumbramiento; se está ante un conocimiento que deslumbra y no penetra», por eso la perplejidad "aparece en época avanzada de una cultura» inevitablemente y "andar perplejo es estar entre varias alternativas sin decidirse por ninguna», situación que se da "cuando el conocimiento es tal que deja margen al riesgo, cuando al elegir tenemos que arriesgarnos», al perplejo "le falta ese último móvil que mueve a la vida, que le arrastra y saca de sí»» ${ }^{42}$. Es ésta una situación que se reitera en las culturas, una vez alcanzado un cierto nivel de desarrollo, y crea un momento de sobresaturación y estancamiento por indecisión.

No es María Zambrano la única que ha reparado en la importancia de atender a este tipo de situaciones. Como se sabe, la figura del "espectro», introducida por Derrida, para pensar la posibilidad de la historia, la temporalidad, y también el porvenir y la memoria, sitúa en la inseguridad e indecidibilidad que supone el exceso, intentando mostrar el sentido positivo de asumir esta situación que obliga a instaurar otra lógica: la de lo imprevisible en la repetición, inasumible por el cálculo o la dialéctica superadora.

Los Dos fragmentos acerca del pensar, publicados en Orígenes en 1956, recogen ideas básicas del pensamiento de Zambrano que, como tales, habían aparecido en sus primeros escritos, llevando la marca de su formación orteguiana, pero se mantendrán incluso tras la inflexión que supone la adopción de la racionalidad poética, en las obras posteriores a los Claros del bosque. Por otra parte, en estas páginas, redactadas en Roma, no puede pasarse por alto la

\footnotetext{
${ }^{42}$ ZAMBRANO M., "La Guía, forma del pensamiento», en Hacia un saber sobre el alma, Madrid, Alianza, 2000, pp. 94-95.
} 
incidencia de figuras como la de E. Zola, cuya consideración de la tradición como forma en la que el saber se articula- tiende a confirmarla en el convencimiento de que la filosofía se define por el pensar que es distancia, pregunta y sistema, "pobreza inevitable» respecto al saber, pero acción propiamente humana, mediante la que el ser humano nace, va «naciendo, abriendo posibilidades», dice, porque "si el saber fuese lo adecuado a la condición humana, el hombre hubiera podido permanecer en las culturas de sabiduría, en algunas de las cuales se supo mucho de lo que ahora descubrimos, mucho quizá de lo que está al descubrirse. Mas si el saber es el imán del pensamiento, una vez logrado se acumula y se alza como pasado frente al hombre. Mientras que el pensar es acción, insustituible acción, en la que se revela la esencia de la condición humana; descubrir la ignorancia rescatando su libertad. Y sólo así se abre el futuro».

Estas palabras aparecerán literalmente de nuevo en sus Notas de un méto$d o^{43}$, donde sus primeras reflexiones recuerdan que «si la filosofía existe como algo propio del hombre, ha de poder franquear distancias históricas, ha de viajar a través de la historia; y aún por encima de ella, en una suerte de atemporalidad $»^{44}$, pero indicando también que, por eso, encierra un olvido originario en el que se separa de la vida: «Ha sido una especie de imperativo de la filosofía, desde su origen mismo, el presentarse sola, prescindiendo de todo cuanto en verdad ha necesitado para ser. Mas lo ha ido consumiendo o, cuando así no lo conseguía, lo ha dejado en la sombra, tras de su claridad. Así es como la experiencia de la vida queda separada del pensamiento, que en su pureza diamantina está destinado a ser consumido por alguien; alguien que al asimilarlo hará que entre en su experiencia, que será el vaso donde el pensamiento filosófico se deshace y se rehace para ser bebido. Pues que el pensamiento no sucede a solas en la mente de quien lo acoge, a no ser que lo acoja sin que lo necesite. $Y$ aunque se olvide de todo lo que como ser humano le pasa, le ha de pasar igualmente y en modo inequívoco el pensamiento que le llega» ${ }^{45}$.

El filosofar de esta autora discurre, desde el comienzo, atendiendo a lo que, consumido, permanece en la sombra, para, llevándolo a la luz, permitir que transite y para obtener de ello su vitalidad. En su caso es tan clara la vinculación de su escritura a un doble nivel de necesidad -el marcado por lo que, desde dentro impulsa a expresarse y el que delimitan los requerimientos de la existencia- que no vale la pena insistir ahora en ello, y es también tan complejo el modo en que los dos niveles se implican, que tampoco sería posible hacerlo; basta recordar su convencimiento de que «no se escribe ciertamente por necesidades literarias, sino por la necesidad que la vida tiene de expresarse ${ }^{46}$. A esta necesidad corresponde el género literario de la confesión y, de hecho,

\footnotetext{
${ }^{43}$ ZAMBRANO M., Notas de un método, Madrid, Mondadori, 1989, p. 106.

${ }^{44}$ O.c., p. 16.

${ }^{45}$ O.c., p. 15.

${ }^{46}$ ZAMBRANO M., La confesión: género literario, Madrid, Siruela, 1995, p. 25.
} 
en la narración del pasado, que busca abrir el futuro, emprendida en los primeros años de su exilio, su lectura de la historia la presenta a modo de «confesión colectiva» como particular forma del uso público de la razón: «Actualmente lo histórico es la mayor urgencia, el quehacer más serio del hombre y por ello mismo es necesaria una rememoración, un echar la vista atrás, precisamente para liberarnos de nuestro pasado. Esta cuestión del pasado es hoy una de las más graves y no se puede dejar por más tiempo en manos del "tradicionalismo", de cualquier género de tradicionalismo. La tradición no es sino la buena circulación histórica, cuando el pasado sin estancarse fluye dejando paso al porvenir. Pero cuando el pasado se solidifica y estanca, entonces el porvenir se ve obstruido y llega a producirse una situación insostenible $»^{47}$.

Cuando, ya en Roma, vuelva sobre la relación con la tradición, sobre el modo de hacer de ella «circulación histórica», proporcionará de nuevo indicaciones fundamentales que apuntan a la necesidad de tomar la situación propia como punto de referencia: «Muchos saberes han desaparecido reabsorbidos en la ignorancia porque eran fragmentarios y su unidad meramente acumulativa al no ser sistemáticos. Sabidurías enteras han podido perderse y se han perdido de hecho; sus restos son arrastrados luego en forma de supersticiones, de vagos recuerdos o de aseveraciones herméticas, a la manera de una escritura musical de la que se ha perdido la clave. Nada extraño es lo que a menudo sucede cuando, al fin, se logran descifrar textos de antiguas culturas que hacían esperar nos traerían un tesoro de saber y que tan poco nos han ofrecido. No por descifradas y traducidas pueden ser asimiladas por nuestra mente; para lograrlo tendríamos que extraer de ellas el pensamiento clave de donde partieron, si lo había, y caso de no haberlo, el conjunto de creencias que les sirvieron de soporte y revivir las situaciones de donde salieron o para las que fueron solución. Percibirlas desde la zona olvidada de nuestra alma, desde esa memoria ancestral que yace en el olvido $»^{48}$.

Al escribir estas líneas Zambrano no sólo es consciente de la importancia de llevar a lenguaje el pasado como ineludible respuesta a situaciones insostenibles, lo es también del hecho de que, en la sombra, en «la zona olvidada de nuestra mente», habita un pasado constitutivo del presente y no siempre asimilable; sabe ya del «privilegio de tener antepasados». Éste fue el punto de partida de su lectura de Séneca, figura mediadora por excelencia en virtud de su capacidad de permanencia y de renacimiento al arraigar en la vida de un pueblo hasta el punto de revelar su esencia, pero, sobre todo, porque vuelve cuando se le busca ${ }^{49}$, y de ahí el que su actualidad nazca «de las entrañas mismas de nuestro presente». Antepasados como Séneca son, para Zambrano, figuras

\footnotetext{
${ }^{47}$ ZAMBRANO M., «La mujer de la cultura medieval», en Ultra, n 4, La Habana, 1940.

${ }^{48}$ ZAMBRANO M., "Dos fragmentos acerca del pensar», en Orígenes, n 40, La Habana, 1956.

${ }^{49}$ ZAMBRANO M., Séneca, Madrid, Siruela, 1994, sobre todo las páginas sobre la «Actualidad de Séneca», pp. 21-26.
} 
que «como los cuerpos físicos, tienen también resistencia; se nos imponen porque nos limitan [...] Y como criaturas del tiempo ya ido, son enigmas que necesitan una nueva interpretación para liberarnos de su prestigio. Pues todo lo que pertenece al pasado necesita ser revivido, aclarado, para que no detenga nuestra vida ${ }^{50}$.

\section{3. «En el corazón del logos»}

Prescindamos de la forma en la que Zambrano lleva a cabo su personal interpretación de Séneca. Quisiera sugerir a modo de hipótesis que esta manera de leer la historia, rescatando mediaciones en función de la necesidad del presente, tiene que ver no sólo con la de entender qué son los textos, sino con la capacidad de pensar la relación personal con la escritura y con el texto propio. Es ésta una idea sobre la que comencé a reflexionar observando la preocupación explícita de algunos autores por cuestionar su tarea de escritores, reconduciendo su actividad teórica al ámbito de lo privado al que dotaban así de una dimensión pública, radicalmente comprometida desde su misma situación y lo que en ella ponían en juego.

No es necesario recordar que una de las primeras cuestiones que María Zambrano se plantea, en primera persona, es «ipor qué se escribe?»; la respuesta, reiterada a lo largo de su obra, da razón de que, en uno de sus últimos textos, se refiera al libro como algo que «está, de pleno, en la fysis. Sin él, algo faltaría en la creación», algo que, dotado de la virtus de la rosa de Jericó que «con sólo una gota de agua recobra su condición de rosa, exhala un perfume, vive y se apaga después. Y queda así, por tiempo indefinido»-, «es, ante todo, buscado, saboreado, y despide un particular olor», de modo que «las casas, sean palacios, sean templos, quedan deshabitadas cuando en ellas no hay el respiro de un libro. Esa presencia, ese olor, propio de su ser, es, pues, sustancia y esencia a la vez. ¿Cómo se podría vivir en un recinto sin un libro? ${ }^{51}$. Por el mismo motivo vinculará el escribir al filosofar, "pues que ningún filósofo se ha realizado como tal sin ser un gran escritor" ${ }^{\prime 52}$ y matizará la ambigua relación que mantiene con sus propios libros.

En este sentido, el testimonio de otra autora, Jeanne Hersch, en el breve ensayo en el que responde a "ipor qué escribe usted?» ${ }^{53}$, resulta muy esclarecedor en la medida en que remite a una experiencia común: la ambigüedad del escrito radica en que, como tal, adquiere una independencia respecto a su autor, para el que deviene un objeto extraño, cuya extrañeza, sin embargo, se

\footnotetext{
${ }^{50}$ O.c., p. 26.

${ }^{51}$ ZAMBRANO M., «Ser naciente» (1987), en Las palabras del regreso, Salamanca, Amarú, 1995, pp. 111-112.

${ }^{52}$ ZAMBRANO M., «Del escribir» (1985), en Las palabras del regreso, ed. cit., p. 115.

${ }_{53}$ Aparecido en La table ronde, $\mathrm{n}^{\circ}$ 131, 1958 y recogido en el volumen, traducido al italiano, La nascita di Eva. Saggi e racconti, Intelinea, Novara, 2000, con otros ensayos.
} 
torna en expresión esencial de uno mismo ante la mirada de los otros, esto es, cuando se atiende a él en el circuito de la comunicación en el que, por su misma realidad, entra.

En este doble carácter -su capacidad de subsistir con independencia del autor, pero habiendo brotado de la existencia de éste, de cuya acción motivada por la necesidad de la vida es objetivación- radica la vida de los textos que, autores, como Jeanne Hersch, enseñan a recuperar.

No es difícil encontrar sintonías entre estos comportamientos y los del «lector infrecuente» al que George Steiner se refería ${ }^{54}$. Su diagnóstico de la vida intelectual -en la que percibe una suerte de temor a la revelación de lo inmediato $^{55}$ que se expresaría en la opción por el comentario y le induce a reparar en la fuerza formativa de las "presencias reales» que configuran la cultura- no es ajeno a las condiciones de incertidumbre que son la marca de la actualidad y se encuentra en la base de su reivindicación de la lectura como acto de responsabilidad y hospitalidad.

En el prefacio con el que presenta las conversaciones mantenidas con el autor en octubre de 1989 Ramin Jahanbegloo nos habla de su «pasión por leer el mundo $»^{56}$ a partir de la «reciprocidad vitalizante» que posibilita el encuentro con los textos, a los que considera «clásicos» cuando posibilitan una interpretación creadora, convirtiéndose en fuente de errores y de revelaciones, en todo caso, de un diálogo vivo; por ello, «toda lectura es para Steiner una interrogación ontológica y una experiencia de libertad». En su obra convive la afirmación de la «extrema confusión de nuestro mundo» con la voluntad de entender, acompañada de flexibilidad irónica y un característico tono de "cortesía» que sitúa su aportación, según sus palabras, «en el corazón del $\log 0 \aleph^{57}$, centro vital que libera el horizonte del pensar.

\footnotetext{
${ }^{54}$ Véase «El lector infrecuente» (1978) en STEINER G., Pasión intacta, Madrid, Siruela, 1997.

${ }^{55}$ Véase, por ejemplo, STEINER G., Entretiens, París, du Félin, 2000, p. 90.

${ }^{56}$ O.c., p. 14.

${ }^{57}$ O.c., p. 81.
} 
